This is an electronic reprint of the original article. This reprint may differ from the original in pagination and typographic detail.

Author(s): Ojala, Arto; Tyrväinen, Pasi

Title: Developing cloud business models: A case study on cloud gaming

Year: $\quad 2011$

Version:

Please cite the original version:

Ojala, A., \& Tyrväinen, P. (2011). Developing cloud business models: A case study on cloud gaming. IEEE Software, 28(4), 42-47. https://doi.org/10.1109/MS.2011.51

All material supplied via JYX is protected by copyright and other intellectual property rights, and duplication or sale of all or part of any of the repository collections is not permitted, except that material may be duplicated by you for your research use or educational purposes in electronic or print form. You must obtain permission for any other use. Electronic or print copies may not be offered, whether for sale or otherwise to anyone who is not an authorised user. 


\title{
Developing Cloud Business Models: A Case Study on Cloud Gaming
}

\author{
Arto Ojala and Pasi Tyrväinen \\ University of Jyväskylä \\ Cloud computing lets small firms compete in markets traditionally \\ dominated by multinational corporations. Over a ten-year period, one such \\ firm developed a successful cloud-gaming business model.
}

Ever since the software industry diverged from the computer manufacturing industry, software firms' business models have been in flux. Over the last decade, the primary software industry has tended to be seen as a combination of a US\$200-billion software product industry (with products comprising either enterprise solutions or packaged mass-market software) and a $\$ 500$-billion professional-services industry (producing bespoke software systems matching exact customer needs). ${ }^{1}$ In contrast, the vertical software industries' role has been difficult to grasp, existing between the primary software industry and industries purchasing specialized software systems for their core businesses. ${ }^{2}$

One reason for this lack of clarity is the obsolescence of industry classification systems. These tend to conceal the software development activity of media and communication companies such as Apple, Google, Nokia, and AT\&T, classifying them among nonsoftware industries. Another reason is the vague border between traditional software companies, which deliver software as packages but also through the Internet, and software-based firms, which use the Internet in new ways, including as a means to create and capture value from delivering content and services. These services include what have become known as cloud applications.

Cloud computing refers to the provision of computing capacity and applications as a service across the Internet. There are three service layers (matching the cloud architecture layers): ${ }^{3,4}$

- Infrastructure as a service (IaaS) provides computation and storage capacity.

- Platform as a service (PaaS) provides software development tools and an application execution environment.

- Software as a service (SaaS) provides applications on top of PaaS, IaaS, or a private data center.

Here, we focus on the evolution of a small software firm's product and business model, from an SaaS toward a PaaS platform strategy. ${ }^{5}$ In particular, this case study considers how, over time, this firm developed a successful cloud business model to compete in computer gaming.

\section{Business Models}

The term "business model" tends to be loosely defined. Essentially, a business model is a story that explains how a firm works. ${ }^{6}$ However, firms often depend on other actors in the market. So, to understand how a firm works, we must know the other important actors in its network. For this reason, we apply Alexander Osterwalder and his colleagues' recent definition of a business model, which takes the entire firm's network into consideration:

[A business model is] a description of the value a company offers to one or several segments of customers and of the architecture of the firm and its network of partners for creating, marketing, and delivering this value and relationship capital, to generate profitable and sustainable revenue streams. ${ }^{7}$

Business models are often depicted as static descriptions of a firm's activities in the market. However, markets aren't static, and firms must respond to market changes. In addition, a change in a software firm's products can change its business model. So, a business model that succeeds today might not be successful 
tomorrow, and firms must adjust their software offerings and business models to adapt to changing market conditions.

\section{From Packaged Software to SaaS}

For software firms, the transition to an SaaS business model means much more than just delivering standard software products through the Internet (see Table 1). The adoption of SaaS has been regarded as a major driver of structural changes in the software industry. 8,9 SaaS promises software firms more customers because applications become available via the Internet and are no longer limited by the need to package and deliver CDs or DVDs. Moreover, the service is executed in a single virtual environment that removes the need to develop, test, and maintain software variants for multiple OSs, databases, and middleware systems. Estimating future demand for capacity is no longer a problem because the software executes on top of third-party PaaS or IaaS with virtually unlimited capacity in terms of on-demand processing power and storage.

Table 1. Software-as-a-service characteristics, concerns, and business characteristics.

\begin{tabular}{|l|l|l|}
\hline Characteristics & Concerns $^{\mathbf{1 0}}$ & Business characteristics $^{\mathbf{1 1}}$ \\
\hline $\begin{array}{l}\text { Service based } \\
\text { Scalable and elastic } \\
\text { Shared (multitenancy, one-to- } \\
\text { many) }\end{array}$ & $\begin{array}{l}\text { Service-level-agreement guarantees } \\
\text { Security, including data ownership } \\
\text { Integration with on-premise systems; } \\
\text { Usage metering }\end{array}$ & $\begin{array}{l}\text { Easy to deploy, easy to deliver } \\
\text { Online purchase, online support } \\
\text { Low price, high volume } \\
\text { Low competitive advantage } \\
\text { Internet technology }\end{array}$ \\
$\begin{array}{l}\text { Transparency of processes and supply } \\
\text { chains } \\
\text { Immature technology and standards } \\
\text { Common business processes } \\
\text { Lnproven financial and licensing } \\
\text { models }\end{array}$ & $\begin{array}{l}\text { Transferrable risk } \\
\text { Modest internal IT capacity } \\
\text { Immediate need } \\
\text { Low budgetary expense }\end{array}$ \\
\hline
\end{tabular}

The core value of SaaS lies in providing online access to a software product that the provider manages and maintains. For customers, SaaS promises more services for fewer upfront costs because they only pay per use. Moreover, out of the "long tail" of services provided via SaaS, ${ }^{9}$ they can choose the one that best matches their needs, rather than using software they've installed on a PC. This means fewer problems with purchasing, updating, and maintaining computer hardware, or with hard disks, OSs, and applications. The applications are stored on the Internet, upgrades are available automatically, and Internet data storage expands in accordance with demand, never becoming full.

For software firms, the promise of low costs for users is, in one sense, bad news. On the other hand, they can offer low-cost services to small businesses and individual users that could never have afforded heavy enterprise systems in which adoption might well require expensive tailoring and integration. Moreover, large enterprises can also adopt SaaS services on the basis of service flexibility. They find advantages in the ease of starting to use a service or in cases in which prior problems with poor cost/benefit ratios have prevented the use of software.

SaaS doesn't promise "killer" applications for high-end users; rather, the benefits accrue to large numbers of users in new market segments with the provision of services previously available to only a few enterprises. The charges for SaaS services are also based on use. Instead of a large lump sum when a license is sold or a software project is delivered, SaaS offers service providers a fairly steady stream of income once customers have started using the service. However, owing to the low revenue per customer, service providers will need many customers, which they can gain through aggressive marketing or by using high-volume channels, such as network operators. 


\section{The Case Study}

We chose the gaming industry for our case study because games include features from both the software and media industries. The gaming market includes extremes, ranging from high-end games (requiring specialized consoles) to simple games (delivered free through the Internet). Both might seem like challenging markets for SaaS offerings, which can suffer from network latency and rely on end-user payments.

We examined how the software offering and business model of "Game Cluster" (G-cluster) - a software firm that uses cloud architecture in the gaming market-developed from 2000 to 2010. More specifically, we explored the reasons behind the changes to its software and the business model and the benefits these changes precipitated. We conducted two rounds of interviews: one in 2005 and one in 2010. In total, we conducted seven open-ended interviews with five informants, each lasting 45 to 90 minutes. The informants included the managing director, the vice president, the chairman of the board of directors, the vice president of software engineering, and a software engineer. In addition, we followed the firm's press releases and website to gather additional information.

\section{System Architecture}

G-cluster, established in 2000, has 25 employees. It provides interactive gaming platforms and games on demand, summed up as "gaming-as-a-service." The firm's system architecture executes computer games on servers operating the firm's game system platform. It delivers games to client devices (players' TV set-top boxes or PCs) as a compressed stream through the Internet, provided by a broadband network operator. This model frees consumers from worrying about processor power, the OS, graphics cards, or other technical specifications of a PC or console.

Network operators are in a good position to provide customers with the quality of service in the IP connection needed for latency management. They also have large customer bases to target and computing centers that can operate gaming infrastructure services.

\section{The 2005 Software and Business Model}

During G-cluster's start-up phase from 2000 to 2003, it focused mainly on product development and networking with potential partners. In 2003, it started concentrating on marketing and sales.

Figure 1 demonstrates the 2005 business model. In this model, G-cluster licensed source code from other firms, such as game publishers and game developers. When G-cluster licenses a game, it modifies the source code to enable the server's gaming platform to execute the code. It also makes any necessary changes for a given user interface. For instance, if a game was originally developed for a console and Gcluster aims to target it at PCs or Internet Protocol Television (IPTV) devices, it must convert the command button drivers for a remote control or control paddle. In 2005, G-cluster tried to penetrate the IPTV market. However, this market was still undeveloped, and G-cluster couldn't reach enough potential customers. So, the firm started offering games on demand to PC users. 
Figure 1. The 2005 business model. G-cluster licensed source code from game licensors. The games were executed on their gaming platform operated by a network operator and delivered to end-users PCs through portals.

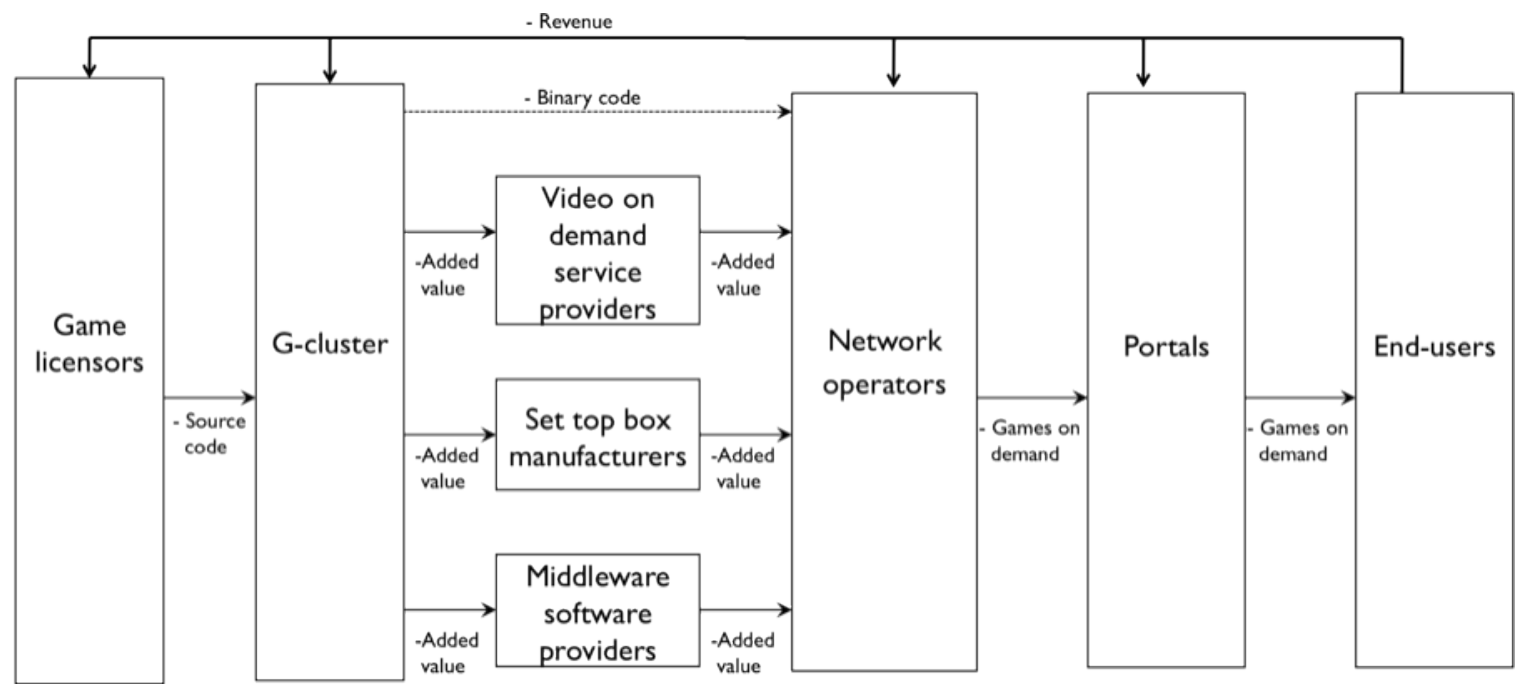

In 2005, G-cluster used network operators and portals as sales channels to consumers. However, it was difficult for such a small firm to contract with network operators. So, G-cluster used value-adding mediators (video-on-demand service providers, set-top box manufacturers, and middleware software providers) as channels to market its product to network operators. In addition, video-on-demand service providers contributed an invoicing system for G-cluster's games-on-demand service. The mediating firms helped G-cluster contract with the network operators who were its main customers. G-cluster provided the gaming platform and game applications for the operators, who ran the games on their servers.

In this business model, portals acted as retailers for G-cluster and the network operators, thus making the games available to consumers. Portals provided game menus for consumers. They also took care of marketing and invoicing through the invoicing system integrated into their own services.

In 2005, the customers of G-cluster's games-on-demand service were mainly PC users, and the service was accessible to 15,000 households. The revenue was shared among the portals, network operators, Gcluster, and game licensors.

\section{Changes in the Software and Business Model}

Figure 2 represents G-cluster's 2010 business model, which is simpler and has fewer actors. It no longer includes video-on-demand service providers, set-top box manufacturers, middleware providers, or portals. This difference has two main causes: a change in the target market and a change in the software provided. 
Figure 2. The 2010 business model. Unnecessary third parties are removed from the business model because of the entire product and changes in the target market.

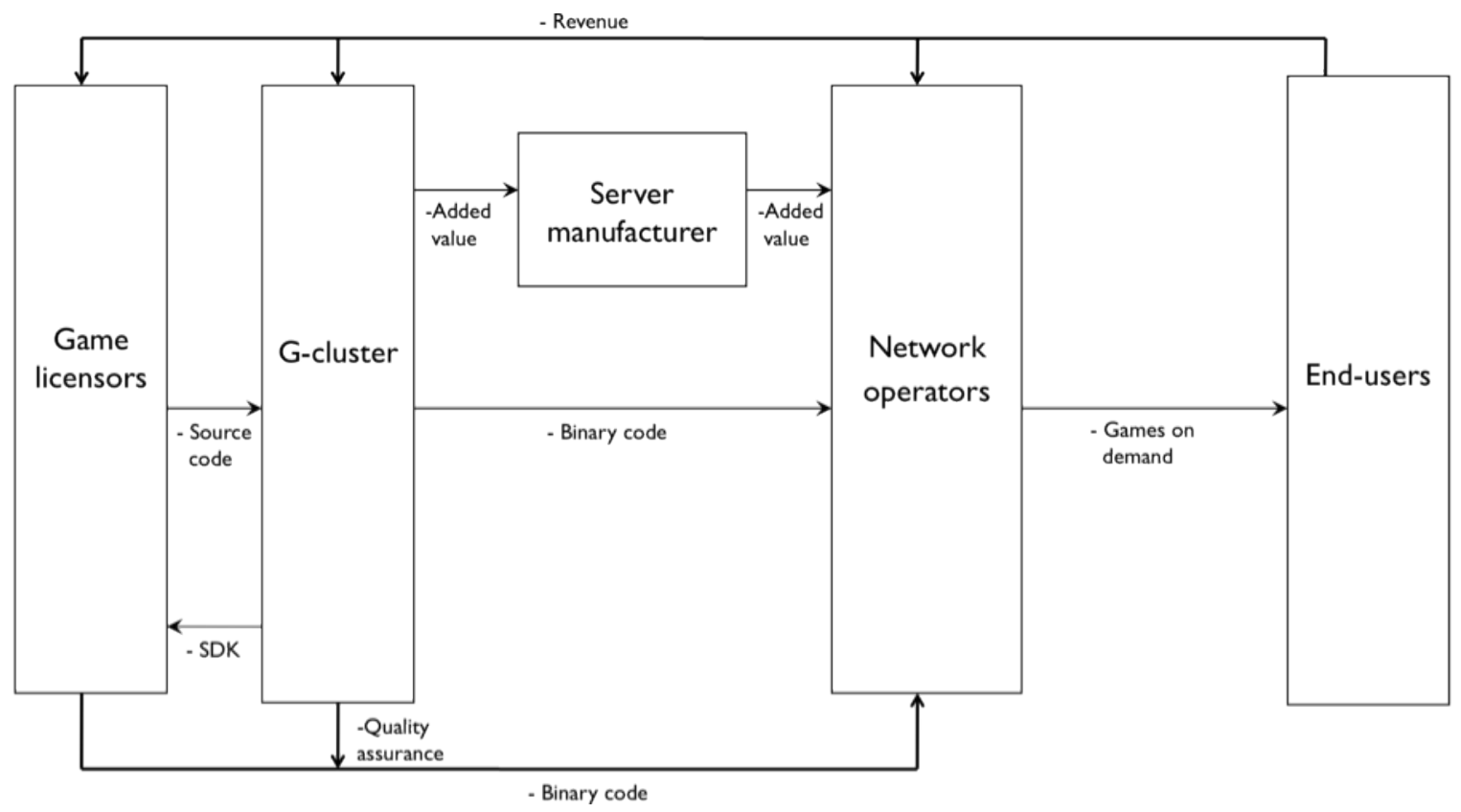

In 2010, the target customers were IPTV users. The PC gaming market had become extremely competitive, and finding a segment on which to focus was hard. For PC players, games have increasingly become free. In addition, well-known games are extremely expensive to license for games-on-demand services. All this meant that the PC market became too difficult to penetrate and develop into a successful business. So, G-cluster focused back on the IPTV market. Nevertheless, operating in the PC market had let the firm test the product, obtain feedback, and gain experience. These opportunities enabled G-cluster to develop the product further for the IPTV market.

The target group for G-cluster's games-on-demand service also crystallized. In practice, the service seems best suited to "mid-class" users. Occasional users are unwilling to pay for the service because free games are available (although they're much simpler than G-cluster's games). Heavy users tend to buy games in stores and play very complex games. They are also willing to invest in consoles and other equipment. G-cluster's service thus appeals to the middle category of users that favors "easy to use" games, which are close to Nintendo Wii games. This middle category forms a very large group, as the success of Nintendo's Wii has shown.

Regarding the software, G-cluster now offers a "whole product" for network operators. ${ }^{12}$ In 2005 , Gcluster provided only the server platform and gaming content. In 2010, it offered a ready-made product portfolio including components previously provided by value-adding mediators or network portals. The firm now includes an invoicing system and a user interface (menu) that lets users select the games from its virtual games store. The comprehensiveness of its offerings has enabled better access to network operators with no need for software components from a large number of intermediaries.

In addition, G-cluster got to know the operators better between 2005 and 2010 and can more readily make direct contact with them. The change in target customers to IPTV users and the individualized menu have let it remove portals from the value chain. Altogether, these changes have made G-cluster less dependent on third parties.

The only third party between G-cluster and the network operators is a large, well-known server manufacturer. G-cluster is still relatively small; thus, cooperation with the large firm helps it negotiate with new network operators. However, G-cluster conducts no actual business with the server manufacturer; instead, the cooperation benefits both firms. G-cluster gets marketing and sale resources from the firm, which already knows the network operators and conducts business with them. By including G-cluster's technology on its servers, the manufacturer gets added value, which it can advertise when selling servers to network operators. 
In the current business model, G-cluster also offers a software development kit (SDK) for game licensors. By using the SDK, licensors can modify and integrate a game directly for G-cluster's gaming platform and send it to network operators. Nevertheless, G-cluster undertakes quality assurance for all games before network operators can offer them to customers. The long-term plan is to outsource all the integration work to game developers. In this way, developers can take the requirements of G-cluster's gaming platform into consideration right from the start. The SDK decreases integration costs and lets Gcluster launch new, more expensive games.

As Figure 2 shows, the revenue is now divided among three actors instead of four. This, together with other business model changes, has doubled the average revenue per user. In addition, G-cluster's service is now accessible to 3,000,000 households.

\section{Lessons Learned}

A business model must provide value to the actors in the supply chain. G-cluster's business model has provided added value to actors in the game services supply chain and to customers. Over five years, both internal changes (product development) and external changes (competition in the PC games market) have impacted G-cluster's business model. The lessons learned from the G-cluster experience are applicable to a broader population - that is, software firms whose business model includes providing cloud services through the Internet.

\section{Aim at a Whole Product}

By adding the invoicing and user interface software, G-cluster created a product that contains all the modules needed and satisfies the operators' needs. ${ }^{12}$ With this business model, G-cluster has become less dependent on third parties and has improved profitability by reducing the number of the partners who share end-user revenue. This implies that firms should simplify the value chain as soon as possible.

Certain third parties were important in G-cluster's start-up phase because they provided knowledge and software modules that the firm didn't have. These parties also acted as marketing channels at a time when G-cluster lacked legitimacy in the market. However, when the firm achieved an entire product and a feasible market position, costly partners became unnecessary.

\section{Shift to a Platform Layer}

G-cluster's development of the SDK made it more profitable to include new games for its service. The new business model decreased G-cluster's modification of games and increased the range of available games. Although this decreased the income per game, it boosted the total volume. So, a shift in emphasis in the architectural layers, from the games layer to the platform layer, let G-cluster focus on developing the core product. Generally, firms must develop alternative business models to keep their products competitive for customers and maintain profitability for revenue-sharing partners.

\section{Balance the Platform Strategy and Operators' Roles}

Network operators can guarantee the quality of gaming-as-a-service. They also possess the customer contacts and have the infrastructure for operating cloud services. A small firm such as G-cluster couldn't achieve the market volume that would let it operate the platform and games on its own, bypassing the operators. So, providing full PaaS software for network operators and associated tools for game licensors has let G-cluster establish a feasible platform strategy in its business model. ${ }^{5}$

\section{Use Indirect Network Effects}

The server manufacturer acted as an important new third party in the business model, even though there were no major business transactions or contracts between it and G-cluster. The partner now acts as a reliable marketing channel, increasing G-cluster's market credibility and helping to find good contacts on the customer side, which will prove useful when G-cluster negotiates with large network operators. This indicates that small software firms should exploit the positive indirect network effects of its partners. 


\section{Exploit SaaS Advantages}

Game licensors appreciate the SaaS model for various reasons. Executing the games on a cloud server makes illegal copying practically impossible. It's also easy to benefit from the long tail when offering SaaS. In a virtual store, shelf space costs nothing, and the licensor can offer a large number of games for longer than traditional games offered in stores_-given that a game's life cycle is relatively short and shelf space is costly.

\section{Adapt to Infrastructure Technology Changes}

The IP protocol has been seen as a unifying platform for future applications. However, a plethora of network variants, infrastructure components, interfaces, and standards wars are still impacting the market reach of any software-based system. As we described, G-cluster changed its business model from IPTV users to PC users - and then back to IPTV users. These changes were based on technical developments and competition in the market. However, these business model changes haven't impacted G-cluster's product strategy because the same gaming platform can deliver games for PC and IPTV. The only technical change was coding the command buttons of the PC games for IPTV users.

For a small software firm such as G-cluster, successful operation in an SaaS market means including feasible positioning in the business model. This means accurate positioning in many dimensions. For Gcluster, the positioning involved providing full gaming platform software and being located between content rights holders and network operators. It also meant serving mid-class gamers with a long tail of games that were previously issued for game consoles and that are now used for games on demand through IPTV devices.

Generally speaking, a business model change might come from outside the firm (a change in the market situation) or inside the firm (development of a new or existing product). When a software vendor starts a firm, develops a new product, or expands a product line, it must evaluate how these changes impact the business model. In addition, in assessing a business model, the vendor should evaluate a new product or service's added value to other actors and customers. As G-cluster's case demonstrates, striving for platform leadership in the market will inhibit the entry of new competitors. Firms can also reduce the threat of competition by developing a business model that benefits all partners, thus making it difficult for newcomers to achieve a foothold in the value chain.

\section{References}

1. D.J. Hoch et al., Secrets of Software Success: Management Insights from 100 Software Firms around the World, Harvard Business School, 2000.

2. P. Tyrväinen, "Vertical Software Industries," Vertical Software Industry Evolution: Analysis of Telecom Operator Software, P. Tyrväinen and O. Mazhelis, eds., Springer, 2009, pp. 11-15.

3. M. Armbrust et al., "A View of Cloud Computing," Comm. ACM, vol. 53, no. 4, 2010, pp. 50-58.

4. L. Youseff, M. Butrico, and D. Da Silva, “Toward a Unified Ontology of Cloud Computing," Proc. 2008 Grid Computing Environments Workshop (GCE 08), IEEE CS Press, 2008, pp. 1-10; doi:10.1109/GCE.2008.4738443.

5. A. Gawer and M. Cusumano, Platform Leadership, Harvard Business Press, 2002.

6. J. Magretta, "Why Business Models Matter," Harvard Business Rev., vol. 80, no. 5, 2002, pp. 86-92.

7. A. Osterwalder, Y. Pigneur, and C. Tucci, "Clarifying Business Models: Origins, Present, and Future of the Concept," Comm. Assoc. for Information Systems, May 2005, pp. 1-40.

8. V. Choudhary, "Software as a Service: Implications for Investment in Software Development," Proc. 40th Hawaii Int'l Conf. System Sciences, IEEE CS Press, 2007, article 209a.

9. C. Anderson, The Long Tail: Why the Future of Business Is Selling Less of More, Hyperion, 2006.

10. D. Greschler and T. Mangan. "Networking Lessons in Delivering Software as a Service, Part I," Int'l J. Network Management, vol. 12, no. 5, 2002, pp. 317-321.

11. J. York, "SaaS Model Economics 101: Competitive Advantage in Software-as-a-Service," blog, 30 Nov. 2008, http://chaotic-flow.com/saas-model-economics-101-competitive-advantage-in-software-a-a-service. 
12. G.A. Moore, Inside the Tornado, Harper Business, 1995. 